\begin{tabular}{|l|l|l||}
\hline \multicolumn{2}{|c|}{ PublisherInfo } \\
\hline \hline PublisherName & $:$ & BioMed Central \\
\hline \hline PublisherLocation & $:$ & London \\
\hline \hline PublisherImprintName & $:$ & BioMed Central \\
\hline \hline
\end{tabular}

\title{
Hopping along DNA
}

\begin{tabular}{|l|l|l||}
\hline \multicolumn{2}{|c|}{ ArticleInfo } \\
\hline \hline ArticleID & $:$ & 3725 \\
\hline \hline ArticleDOI & $:$ & $10.1186 /$ gb-spotlight-20000713-02 \\
\hline \hline ArticleCitationID & $:$ & spotlight-20000713-02 \\
\hline \hline ArticleSequenceNumber & $:$ & 162 \\
\hline \hline ArticleCategory & $:$ & Research news \\
\hline \hline ArticleFirstPage & $:$ & 1 \\
\hline \hline ArticleLastPage & $:$ & 2 \\
\hline \hline & & RegistrationDate : 2000-07-13 \\
ArticleHistory & $:$ & OnlineDate \\
\hline \hline ArticleCopyright & $:$ & BioMed Central Ltd2000-07-13 \\
\hline \hline ArticleGrants & $:$ & \\
\hline \hline ArticleContext & $:$ & 130591111 \\
\hline \hline
\end{tabular}




\section{William Wells}

Email: wells@biotext.com

Oxidative damage yields isolated electrons and their corresponding 'holes' that can migrate along DNA. In the 6 July Nature Lewis et al. determine rate constants of $\sim 5 \times 107 \mathrm{~s}-1$ and $5 \times 106 \mathrm{~s}-1$, respectively, for forward and return hole transport from a single guanine base to a double guanine base across a single adenine (Nature 2000, 406:51-53). These rates mean that electrons do not linger long enough to participate in strand-cleavage reactions. But the electrons move too slowly to avoid charge recombination, so DNA cannot act as a useful molecular wire.

\section{References}

1. Distance-dependent electron transfer in DNA hairpins.

2. Nature, [http://www.nature.com/nature/] 